\title{
Beyond Computers In The Classroom: Factors Related To Technology Adoption To Enhance Teaching And Learning
}

Janet A. Buckenmeyer, Purdue University Calumet, USA

\begin{abstract}
How is technology being integrated to the extent possible toward the goals of improving teaching and learning? Research suggests that teachers will be more likely to try new methods of teaching if certain conditions exist. It is not known which conditions are more likely to influence a teacher's decision to integrate technology into the curriculum. Accordingly, the purpose of this study was to investigate the relationships between technology adoption and conditions such as available resources to support the use of technology, teachers' attitudes toward technology, and adequacy of professional development. Data to address the specific research questions were obtained from secondary-level teachers $(n=144)$ from a suburban school district who participated in professional development and responded to a survey designed for this study. Among other findings, analyses revealed that professional development and available resources were significantly related to technology adoption. Recommendations based on the findings, including implications for professional development, are discussed.
\end{abstract}

Keywords: Technology Integration, Technology Adoption in Schools, Conditions of Adoption

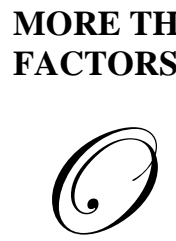

MORE THAN COMPUTERS IN CLASSROOMS: technology does provide teachers and students with a variety of opportunities that were not available previously, including the capability of providing simulations of otherwise costly, time consuming, or dangerous situations, instant global communications, and immediate access to limitless information.

Furthermore, the phenomenon known as the "Digital Divide" illustrates the very real issue that schools do exist that have limited access to technology. While making the technology available is critical, it is only the beginning of the solution. Recent studies have recognized that it is not only the lack of computers that teachers in these poor inner-city and rural schools face. Further barriers include having significantly less training to use technology than teachers in more affluent schools, having technical support systems are not as well funded, and using the available technology in the classroom quite differently (Kleiman, 2000). When considering issues of equity, therefore, all essential conditions for appropriate technology integration need to be examined, not just the number of computers available. Thus, the challenge is not getting appropriate technology into classrooms, but getting those in classrooms prepared to use those technologies, and facilitating greater willingness to incorporate changing technologies as they emerge.

In spite of this potential, school administrators and teachers in the United States still in 2005 remain reluctant to rapidly embrace technological innovation, or to adapt computer technologies that are well-suited to instructional purposes. Access to technology within schools has expanded dramatically; however, a less-dramatic change has been apparent in policies designed to improve the ability of teachers and administrators to use technology effectively (Swanson, 2006). 
As early as 1999, a national survey by Becker (1999) revealed that a majority of teachers - as many as 70 percent-are not using the technologies available to them. The reasons for this are varied and complex. Earlier studies suggest that teachers' educational beliefs play an important role in how they choose to appropriate and make use of technologies in their classrooms (Honey \& Moeller, 1990). For teachers whose beliefs are more traditional, there exist different and more complicated barriers to adoption (Honey \& Moeller, 1990).

The results of a more recent study by Firek (2003) remain disappointingly consistent with Becker's 1999 study: beginning teachers still do not have the skills needed to successfully integrate technology into the curriculum. A teacher's pre-service training may contribute to his or her reluctance to adopt technological solutions. In-service teachers also apparently lack adequate support for technology use. In 1993, Hadley and Sheingold concluded that the access to technology was necessary but not sufficient for making appropriate integration possible. Marcinkiewicz (1994) concluded that simply having more technology does not in itself persuade teachers to begin to use them. Almost a decade later, the report entitled "Teachers' Tools for the $21^{\text {st }}$ Century: A Report on Teachers' Use of Technology," revealed that even now, though the majority of schools had access to some form of technology, a mere one-third of teachers reported feeling well prepared or very well prepared to use computers and the Internet for classroom instruction (National Center for Education Statistics, 2000).

This problem has not abated over time. In fact, the opposite is happening. Consider this statistic: Market Data Retrieval (MDR) data show that the percentage of schools where most teachers are considered "beginner" users of technology has substantially declined, from 35 percent in 1999 to 15 percent in 2005 (Swanson, 2006). We're actually in worse shape when it comes to teacher technology use than we were in 1999.

The reasons for not using technology are numerous, and have been chronicled elsewhere. If student achievement is the ultimate goal, and if technology can be an effective aid in the fulfillment of that goal, then it is logical to assume that teacher implementation of technology will help achieve that goal. Helping teachers to use technology effectively may be the most important step to assuring that current and future investments in technology are realized (OTA, 1995). Anyone who has worked with schools and teachers recognize that the teacher adoption of technology is as much of an issue today as it was ten years ago. The question remains: what factors are related to appropriate incorporation of technology, and what conditions will foster adoption?

\section{RESEARCH QUESTIONS}

Two primary research questions were addressed in this study. First, what are the relationships between the resources available to teachers in support of technology adoption, teachers' attitudes toward technology, teachers' professional development, and teacher use of technology and stage of adoption? Second, what conditions are more likely to promote technology integration into classroom instruction by teachers? That is, what is most important?

These questions are not trivial, but are key to accruing the benefits that technology can offer for teachers and students. The first question attempts to discover if attitude, support for actual use, or professional development opportunities impact the level of use in the classroom? If so, to what extent? The second question, then, follows up on the first: if we know the factors that predict technology integration, what conditions can be put into place by administrators in order to facilitate adoption by a greater number of teachers? If it can be determined what is most needed for teachers to use embrace adoption of available technologies, then perhaps the figure can be transformed from the current $70 \%$ (or $85 \%$ ) of teachers who do not use technologies in their classrooms to $70 \%$ (or $85 \%$ ) who do. Because much computer technology already in classrooms is not being used to realize the potential benefits for teaching and learning that they have to offer, it makes sense to pursue a national policy of "No Computer Left Behind." This policy begins with studying the diffusion of this innovation, so that the conditions can be replicated

\section{METHODS}

The present research was conducted with educators $(n=144)$ who participated in a professional development program related to the use of educational technology. All of the participants were certified teachers or other school personnel working in two large suburban high schools in a Midwestern state. The sample could be considered homogeneous because the characteristics of the teachers and the school population are typical of a 
suburban population; the majority of both populations is white and middle or upper-middle class, and a large percentage of the families is considered "white-collar" workers. Further, more than 80 percent of the surveyed teachers have taken post-baccalaureate classes, with about 60 percent earning a Master's degree. Each school averages about 1500 students per year and average class size is 20 students. At least 89 percent of the respondents reported that they owned a computer and used it in some capacity. However, only 38 percent of the teachers reported that they had received any formal training or had been certified at a novice level of use, according to Ohio SchoolNet guidelines. Table 1 summarizes the demographic characteristics of the participants.

Table 1: Demographic Characteristics Of Participants

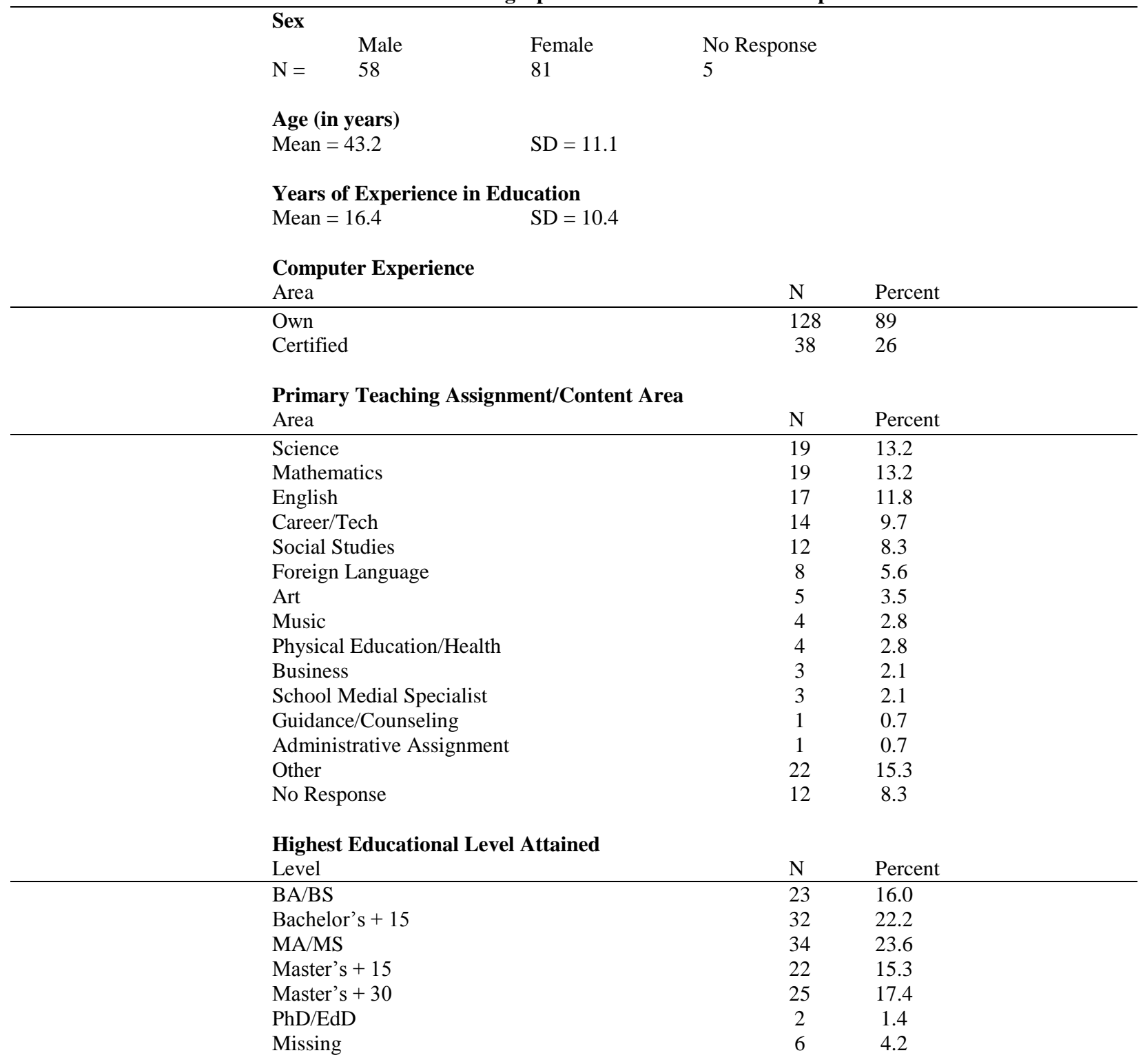

A survey was developed and administered to all participants. Excluding demographic items, the survey consisted of 75 items formatted as Likert-type statements to which participants responded with a rating of $1-5$. Seventy-four of the items comprised four subscales, three of which were considered to be predictors of technology adoption. The predictor subscales are identified as: Professional Development, Available Resources and Support, and Attitude toward Technology. These subscales were conceptualized as measuring the impact of professional 
development, the extent of available resources and support for technology use, and attitude and self-efficacy with respect to the use of technology for teaching and learning. The fourth subscale, Technology Adoption/Use, served as the criterion variable and was a direct measure of participants' adoption and use of technology for educational purposes. One additional item asked participants to classify themselves according to one of six specific adoption stages. The Stage of Adoption variable included the following levels, sequentially from lowest to highest: Awareness, Learning the Process, Understanding and Application, Familiarity and Confidence, Adaptation to Other Contexts, and Creative Application to New Contexts.

\section{RESULTS}

Findings from this study can be grouped into three areas. First, analyses were performed to evaluate the instrument itself. Second, relationships between the predictor and criterion variables were examined, as were relationships between specific items included on various subscales and the criterion variables. Finally, regression analyses were conducted to evaluate the relative contributions of the three subscales and to assess the overall predictive power of a model in which the three subscales were used to predict adoption and use of technology. Results of each of these groupings of analyses are presented in the following subsections.

\section{Instrument Evaluation}

For each of the three predictor subscales, summary data were obtained and reliability analyses were conducted, and subscale intercorrelations were computed. Additionally, data on the Stage of Adoption variable were summarized. Results of these analyses are presented in Table 2. As the results shown in the table demonstrate, the survey yielded highly dependable data, with all subscale and total scale reliabilities above .80. Also, with the exception of the correlation between Available Resources and Support and Technology Adoption/Use which was not statistically significant, all of the subscales were moderately and statistically significantly correlated, suggesting that the subscales measured related, though relatively unique aspects. Further, the correlation between these subscales may actually be underestimated; the modest strength of the correlations obtained in this study may be the result of the fairly homogeneous sample used. Further research may be warranted to discover the extent to which such homogeneity is typical in other settings.

Table 2: Subscale And Criterion Variable Summary Statistics, Reliabilities, And Intercorrelations

\begin{tabular}{llll}
\hline & \multicolumn{2}{c}{ Subscale Analyses } & $N$ \\
Subscale & Number of Items & Reliability (Alpha) & 139 \\
\hline Professional Development & 14 & .84 & 138 \\
Available Resources \& Support & 20 & .93 & 138 \\
Attitude toward Technology & 24 & .90 & 135 \\
Technology Adoption/Use & 16 & .93 &
\end{tabular}

\begin{tabular}{lllll}
\multicolumn{4}{c}{ Subscale Intercorrelations } \\
Subscale & $\begin{array}{l}\text { Professional } \\
\text { Development }\end{array}$ & $\begin{array}{l}\text { Available } \\
\text { Resources }\end{array}$ & $\begin{array}{l}\text { toward } \\
\text { Technology }\end{array}$ & $\begin{array}{l}\text { Technology } \\
\text { Adoption/Use }\end{array}$ \\
\hline Professional Development & & $.391^{* *}$ & $.566^{* *}$ & $.329^{*}$ \\
Available Resources \& Support & --- & & $.275^{* *}$ & -.157 \\
Attitude toward Technology & --- & --- & $.504^{* *}$ \\
Note: $* *=p<.01$, two-tailed & & & &
\end{tabular}

\begin{tabular}{lcc} 
& Stage of Adoption & \\
Stage & $N$ & Percent \\
\hline Awareness & 1 & 0.7 \\
Learning the Process & 11 & 7.6 \\
Understanding and Application & 19 & 13.2 \\
Familiarity and Confidence & 37 & 25.7 \\
Adaptation to Other Contexts & 32 & 22.2 \\
Creative Application to New Contexts & 33 & 22.9 \\
Missing & 11 & 7.6
\end{tabular}


Beyond the findings related to instrument quality lies the first substantive finding of this research: each of the variables (i.e., the subscales Professional Development, Resources, and Attitude toward Technology) was correlated with the primary outcome variable (Technology Adoption/Use) as hypothesized. That is, Professional Development and Attitude toward Technology were both moderately positively related to Technology Adoption/Use, while the extent of Available Resources and Support was not significantly related to Adoption/Use. This finding confirms previous research suggesting that the availability of computing technology in classrooms is not a barrier. The significant correlation between Professional Development and the criterion of Adoption/Use $(\mathrm{r}=.329)$ indicates that technology tends to be more readily adopted in the presence of relevant professional development activities or experiences.

\section{Relationships Between Individual Items And Technology Adoption/Use}

Correlation coefficients were also calculated to describe the relationship between all individual items in the subscales and the criterion, Technology Adoption/Use. Because it is not feasible to provide all correlations here, a sample of item-to-total correlations is provided in Table 3, along with a key to interpretation of the Likert scale points. Table 3 also shows the wordings of three representative items from each subscale.

Table 3: Scale Point Descriptions And Sample Item Information

\begin{tabular}{ll}
\hline Scale Values RangeInterpretation & Scale \\
\hline $4.6-5.0$ & Strongly Agree or Highly Proficient \\
$3.6-4.5$ & Agree or Above Average Proficiency \\
$2.6-3.5$ & Undecided or Moderate Proficiency \\
$1.6-2.5$ & Disagree or Slightly Proficient \\
$1.0-1.5$ & Strongly Disagree or Not Proficient
\end{tabular}

Sample Subscale Items, Means, Standard Deviations, and Item-Total Correlations Professional Development Subscale

Item Wording

1) "Using a trial and error approach has increased my

knowledge of computer use."

2) "Periodicals/professional literature related to computer

use has increased my knowledge on use of computers."

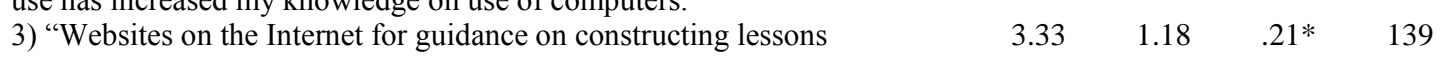

are helpful to me for integrating computer use into my classroom

practice."

Available Resources/Support Subscale

1) I need more training with technology.

2) I need more examples in the use of technology in my

content area"

3) I need more time to learn to use computers.

$\begin{array}{lcll}\text { Mean } & \text { SD } & \mathrm{r} & \mathrm{n} \\ 3.94 & .97 & .37 * * & 143 \\ 2.40 & 1.24 . & 34 * * & 143 \\ 3.33 & 1.18 & .21 * & 139\end{array}$

Attitude toward Technology Subscale

1) "My role as the teacher will be dramatically changed because
of the Internet within the near future." $\quad \begin{array}{llll}3.31 & 1.05 & .290^{* * *} & 143\end{array}$

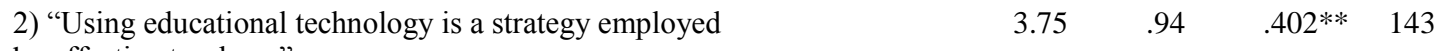

by effective teachers."

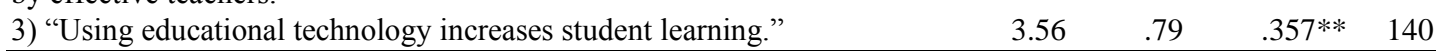

Note: $*=\mathrm{p}<.05 ; * *=\underline{p}<.01$

Among the individual relationships between Professional Development items and Technology Adoption/Use, it is interesting to note that several training activities were significantly correlated to technology adoption. Included among those activities were using a trial and error approach, the use of professional literature, and the use of Internet websites for constructing lessons and designing strategies. Although the overall correlation 
between the subscales of Available Resources and Support and Adoption/Use was nonsignificant, several individual items are noteworthy. For example, as shown in Table 3, items tapping the extent to which participants believe that have enough training in technology — and desire additional support in that area-showed significant relationships to their current level of adoption and use of technology. Finally, as would be predicted based on previous research, participants' attitudes toward technology showed demonstrable relationships to their adoption and use; the sample items from this subscale are illustrative of the strong and uniform relationships in this area.

\section{Regression Analyses}

The final analyses performed were a pair of regression analyses to determine the relative contributions of the three components and to assess the overall predictive power of a model in which the three components were used to predict adoption and use of technology. In the first analysis, the three subscale total scores were used as independent variables and the total score on Technology Adoption and Use served as the dependent variable. In the second analysis, the same independent variables were used, but in this case, the dependent variable was the participant's current Stage of Adoption. Results of these analyses are presented in Table 4.

Table 4:Results Of Regression Analyses

Analysis 1: Dependent Variable = Technology Adoption/
Use Model Coefficients and Significance of Predictors
\begin{tabular}{|l|c|c|c|c|c|}
\hline & Unstandardized Coefficients & Standardized Coefficients & \multicolumn{2}{c|}{ t } & \multicolumn{1}{c|}{ Sig. } \\
\cline { 2 - 7 } & B & Std. Error & Beta & 3.162 & .002 \\
\hline Constant & 22.676 & 7.172 & & 2.471 & .015 \\
\hline Professional Development Total & .318 & .129 & .223 & -4.348 & .000 \\
\hline Available Resources Total & -.300 & .069 & -.334 & .481 & .000 \\
\hline Attitude toward Technology Total & .471 & .086 & .481 & 5.477 & .000 \\
\hline
\end{tabular}

\begin{tabular}{|c|c|c|c|c|c|}
\hline \multicolumn{6}{|c|}{ Model Summary } \\
\hline & Sum of Squares & df & Mean Square & $\mathbf{F}$ & Sig. \\
\hline Regression & 7352.385 & 3 & 2450.795 & 24.421 & .000 \\
\hline Residual & 12042.736 & 120 & 100.356 & & \\
\hline Total & 19395.121 & 123 & & & \\
\hline
\end{tabular}

\begin{tabular}{|c|c|c|c|}
\hline R & R Square & Adjusted R Square & Std. Error of the Estimate \\
\hline .616 & .379 & .364 & 10.01779 \\
\hline
\end{tabular}

\section{RESULTS OF REGRESSION ANALYSES}

\begin{tabular}{|c|c|c|c|c|c|}
\hline \multicolumn{6}{|c|}{$\begin{array}{l}\text { Analysis 2: Dependent Variable = Stage of Adoption } \\
\text { Model Coefficients and Significance of Predictors }\end{array}$} \\
\hline & \multicolumn{2}{|c|}{ Unstandardized Coefficients } & \multirow{2}{*}{$\frac{\text { Standardized Coefficients }}{\text { Beta }}$} & \multirow[t]{2}{*}{$\mathbf{t}$} & \multirow[t]{2}{*}{ Sig } \\
\hline & $\mathbf{B}$ & Std. Error & & & \\
\hline Constant & 1.884 & .810 & & 2.327 & .022 \\
\hline Available Resources Total & -.027 & .008 & -.306 & -3.559 & .001 \\
\hline Attitude toward Technology Total & .031 & .010 & .310 & 3.140 & .002 \\
\hline Professional Development Total & .039 & .015 & .266 & 2.627 & .010 \\
\hline
\end{tabular}

\begin{tabular}{|l|c|c|c|c|c|}
\hline & Model Summary & Mean Square & Sig. \\
\hline Regression & Sum of Squares & df & 15.561 & 12.748 & .000 \\
\hline Residual & 46.683 & 3 & 1.221 & & \\
\hline Total & 142.821 & 117 & & & \\
\hline
\end{tabular}

\begin{tabular}{|c|c|c|c|}
\hline R & R Square & Adjusted R Square & Std. Error of the Estimate \\
\hline .496 & .246 & .227 & 1.105 \\
\hline
\end{tabular}


As the results in Table 4 demonstrate, the combinations of subscales are significant predictors for both Technology Adoption and Use and Stage of Adoption. Not only are the combinations of predictors significant in both cases $(\mathrm{p}<.001)$ but the models as a whole are fairly powerful, with these three variables predicting approximately $38 \%$ and $25 \%$, respectively, of the variance in outcomes. Further, the independent variables in each model are each singly significant predictors. Interestingly, the relative contribution of predictor varies, depending on the dependent variable. For example, the variable Attitude toward Technology is the strongest predictor of the criterion Technology Adoption/Use, while Available Resources and Support is the most powerful predictor for Stage of Adoption.

\section{DISCUSSION}

As has been noted elsewhere, integration of the computer into the curriculum often lags primarily due to soft factors (Ertmer, 1999). Teachers use computers; however, that use has not extended to effective integration. Several implications for technology adoption and the change process in the K-12 environment are suggested by the results of this study. It would seem that certain factors must be present in order to facilitate the embrace of emerging technologies by those in classrooms.

This study addressed two issues. The first line of investigation involved an exploration of the relationships between attitude toward technology, available resources and support, and professional development together and technology use by teachers, including the current stage of adoption. Clearly, the data supports that such relationships exist. Twenty-five to almost forty percent of the change in teachers' stage of adoption and use of technology can be explained by the presence of these three factors. That is, it is the convergence of the teacher attitude, the professional development they receive, as well as the access to available resources and support that makes appropriate integration possible (NCES, 2000; Hadley and Sheingold, 1999). The first implication from this study supports previous research confirming that it the unique combination of factors that facilitates appropriate integration.

Once it was established that the combination of the factors was considered predictive, the relative weight or importance of the individual factors and their contribution to technology use and adoption was examined. Singly, each individual factor was a predictor of technology use and stage of adoption. Even more interesting, attitude toward technology was found to be the strongest predictor of teacher technology adoption and use, while having available resources and support was the most powerful predictor for stage of adoption. This line of thought is developed more fully below.

This study also investigated the relationships between individual items, or factors, surveyed and teacher technology integration. The following recommendations are gleaned from the reported strength of the teacher responses as well as the results of the regression analysis.

First, increased professional development opportunities should be afforded to educators who are called on to increase the effective use of technology for instructional purposes. Technology integration can be promoted by integrating technological applications with traditional content-based professional development opportunities. Technology-specific training activities can also be less formal, in which teachers work together to learn new technologies, and trial and error approaches are encouraged. This finding is supported by the literature which states that technology integration does happen when teachers are prepared to use it (NCES, 2000; Becker, 1999).

Second, additional time (support) must be allocated to the technology needs of educators. Time is needed both to learn new technologies themselves and to learn to integrate those technologies in the classroom (Maney, 1999; Sandholtz, Ringstaff \& Dwyer, 1997; OTA, 1995; Hadley \& Sheingold, 1993). In a study by Franklin, Turner, Kariuki and Duran (2002), technology mentors indicated that the teachers took longer than expected to gain new computer knowledge and skills. This finding and recommendation is consistent with that offered by Vannatta and Fordham (2004) who found that the teacher attributes of time commitment to teaching, an openness to change, and professional development opportunities best predicted technology integration. Most important, time spent on learning and using technology has a positive relationship with technology achievement (Liu, Maddux, \& Johnson, 2004). When not enough time is provided, teachers often resort to what is already known, and so fail to try new methods to teach students. 
Third, adequate technical assistance (support) must be provided to support technology adoption and that support must be timely (Maney 1999; McKenzie, 1999). If equipment is not going to work, and if no one is available to help when the inevitable operational problems occur, then even the teachers who use technology may become frustrated and abandon beneficial tools.

Finally, a consistently strong predictor of adoption and use of technology is attitude toward technology. Attitudes are important to the process of technology adoption (Marcinkiewicz, 1994; Honey \& Moeller, 1990). Teachers are the implementers of change. This notion underlies curriculum dissemination and program replication, and drives educational policy (Craig, 2006). Attitude toward technology plays a key role in shaping teacher use of technology in classroom practice (McGrail, 2005). Ertmer (2005) suggests that in order to change teacher beliefs, research needs to be done in the areas where teachers have first-hand experiences with technology, vicarious experiences where teachers observe successful implementation, and social-cultural influences through professional learning communities. In general, teachers need to see the effectiveness of technology on student learning outcomes. Effective technology integration will only occur through sustained training and professional development activities, which requires time allotted to that purpose.

In summary, this research adds to and reinforces what we know about adoption and use of technology by discovering more about the relationships between the resources available to teachers in support of technology adoption, teachers' attitudes toward technology, teachers' professional development, and both their adoption/use of technology and their stage of adoption. Second, this study has helped identify the conditions most likely to promote technology integration into classroom instruction by teachers.

Obviously, replication of this study would be warranted to the extent that the characteristics of the sample differ from those in other locations. In addition, it is noted that this study is using self-reported data for its analysis and conclusions. The limitations from using this type of data are inherent; the usefulness from the data are only as strong as the quality of the responses. However, to the extent that these teachers are similar in their needs and perspectives to others, this research suggests practical approaches that can be pursued to assist those interested in fostering the process of technology adoption.

If change is to occur in the classrooms, it must begin with the teacher, not the technology. In this article, additional light has been shed on the factors that will promote teachers' embrace of change. Of course, there is much additional to be learned. Ideally, replications and extensions to this research will help to refine what we know and, ultimately, a set of research-based guidelines might be established to promote effective technology integration toward the goal of instructional improvement and increased learning.

\section{AUTHOR INFORMATION}

Janet Buckenmeyer, Ph.D. is an Assistant Professor and Program Chair of the Instructional Technology Program for the Graduate School of Education at Purdue University Calumet. She teaches courses in appropriate technology integration, learning theories and technology, instructional design, and web-based instruction. Her research interests focus on technology integration and student learning, teacher preparation, and educational change. Dr. Buckenmeyer received her PhD in Curriculum and Instruction from the University of Toledo in 2001.

\section{REFERENCES}

1. Becker, H. J. (1999). Internet use by teachers: Conditions of professional use and teacher-directed student use. Teaching, Learning and Computing: 1998 National Survey, Report \#1. [online] 31 pages. Available: http://www.crito.uci.edu/TLC.findings/Internet-use/startpage.htm

2. Craig, D.J. (2006). Why is dissemination so difficult? The nature of teacher knowledge and the spread of curriculum reform. American Educational Research Journal, 43(2), 257-293.

3. Ertmer, P.A. (2005). Teacher pedagogical beliefs: The final frontier in our quest for technological integration? Educational Technology Research \& Development 53(4), 25-39.

4. Ertmer, P.A. (1999). Addressing first and second order barriers to change: Strategies for technology integration. Educational Technology Research \& Development 47(4), 47-61. 
5. Firek, H. (April 2003). One order of ed tech coming up... You want fries with that? Phi Delta Kappan, 84, 596-597.

6. Franklin, T., Turner, S., Kariuki, M., \& and Duran, M. (2002). Mentoring overcomes barriers to technology integration. Journal of Computing in Teacher Education 18(1), 26-31.

7. Hadley, M. \& Sheingold, K. (1993). Commonalities and distinctive patterns in teachers' integration of computers. American Journal of Education 101(3), 261-315.

8. Honey, M. \& Moeller, B. (1990). Teachers' beliefs and technology integration: Different understandings. Technical Report Issue No. 6. Washington, D.C.: Office of Educational Research and Improvement.

9. Kleiman, G. M. (2000, April-June). Myths and realities about technology in K-12 schools. LNT Perspectives: The Online Journal of the Leadership and the New Technologies Community, 14. [online] 9 pages. Available; http://www.edc.org/LNT/news/Issue14/feature1.htm

10. Liu, L., Maddux, C. \& Johnson, L. (2004). Computer attitude and achievement: Is time an intermediate variable? Journal of Technology and Teacher Education 12(4), 593-607.

11. Maney, J. K. (1999). The role of technology in education: Reality, pitfalls, and potential. In G. J. Cizek (Ed.), Handbook of educational policy (pp. 387-415). San Diego, CA: Academic.

12. Marcinkiewicz, H. R. (1994). Computers and teachers: Factors influencing computer use in the classroom. Journal of Research on Computing in Education, 26(2), 220-237.

13. McGrail, E. (2005). Teachers, technology and change: English teachers' perspectives. Journal of Technology and Teacher Education 13(1), 5-24.

14. McKenzie, J. (1999, March). Secrets of success: The ten most important staff development lessons. Session presented at: Michigan Association for Computer-related technology Users in Learning Conference, Detroit, MI.

15. McKenzie, J. (1999). How teachers learn technology best. Bellingham, WA: FNO Press.

16. McKenzie, J. (1999). The technology in my life survey. From Now On The Educational Technology Journal [online]. Available: http://emifyes.iserver.neet/fromnow/techlife.html

17. McKenzie, J. (1998). Secrets of success: Professional development that works. eSchool News [online] 11 pages. Available:http://www.fromnowon.org/eschool/secrets.html

18. Sandholtz, J. H., Ringstaff, C, \& Dwyer, D. C. (1997). Teaching with technology: Creating studentcentered classrooms. New York: Teachers College Press.

19. Swanson, C.B. (2006). Tracking U.S. trends. The Information Edge: Using Data to Accelerate Achievement, 25(35), 50-53.

20. U.S. Congress, Office of Technology Assessment. (1995). Teachers and technology: Making the connection. Washington, DC: U.S. Government Printing Office.

21. U.S. Department of Education, National Center for Education Statistics. (2000). Teachers' tools for the $21^{s t}$ century: A report on teachers' use of technology. Washington, DC: U.S. Government Printing Office.

22. Vannatta, R. A., \& Fordham, N. (2004). Teacher dispositions as predictors of classroom technology use. Journal of Research on Technology in Education 36(3), 253-271. 
NOTES 